\title{
Influência de subprodutos de oleaginosas sobre parâmetros ruminais e a degradação da matéria seca e da proteína bruta
}

\author{
[Influence byproducts of oleaginous on ruminal parameters and degradation of dry \\ matter and crude protein] \\ V.C. Santos ${ }^{1}$, J.M.B. Ezequiel ${ }^{1}$, E.S. Morgado ${ }^{1}$, A.C. Homem Júnior ${ }^{1}$, V.R. Fávaro ${ }^{1}$, \\ A.P. D'Aurea', S.F. Souza ${ }^{2}$, J.C. Barbosa ${ }^{1}$ \\ ${ }^{1}$ Faculdade de Ciências Agrárias e Veterinárias - UNESP- Jaboticabal, SP \\ ${ }^{2}$ Embrapa - Tabuleiros Costeiros - Aracaju, SE
}

\section{RESUMO}

Avaliou-se o efeito da adição de subprodutos de oleaginosas na dieta de ovinos em substituição ao farelo de soja. Foram distribuídos quatro ovinos Santa Inês, com peso corporal de, aproximadamente, 40kg, canulados no rúmen, em quadrado latino $(4 \times 4)$, com quatro dietas e quatro períodos, analisados por regressão para a avaliação da degradação ruminal, dos valores de pH e das concentrações de nitrogênio amoniacal in vivo. Os subprodutos foram as tortas de amendoim, girassol e soja, em dietas isonitrogenadas, com $70 \%$ de concentrado e $30 \%$ de volumoso (feno de tifton). Não foi observado efeito da interação tempo $x$ dieta para os valores de $\mathrm{pH}$ e concentração ruminal de nitrogênio amoniacal $(\mathrm{P}>0,05)$. $\mathrm{O} \mathrm{pH}$ apresentou valor médio de 6,2. As concentrações ruminais de nitrogênio amoniacal não foram afetadas, com valor médio de $29,9 \mathrm{mg} / \mathrm{dL}$. Não foram observadas diferenças $(\mathrm{P}>0,05)$ nas taxas de degradação da matéria seca e na degradabilidade potencial.

Palavras-chave: concentração ruminal de amônia, degradabilidade, $\mathrm{pH}$, tortas de oleaginosas

\begin{abstract}
The aim of this work was to evaluate the introduction of oleaginous byproducts in sheep feeding as a replacement for soybean meal. Four sheep weighing 40kg, with cannulated rumen were selected in a Latin Square (4x4) design, with for diets and four periods analyzed by regression for ruminal degradability evaluate, $\mathrm{pH}$ values and ammonia nitrogen concentration in vivo. Byproducts were the following cakes: peanut, sunflower and soybean, in isonitrogenous diets with $70 \%$ concentrate and $30 \%$ roughage (tifton hay). There was no effect of diet $x$ time interaction for $\mathrm{pH}$ and ruminal concentrations of ammonia nitrogen $(P>0.05)$. The average $p H$ value was 6.2. Ruminal concentrations of ammonia nitrogen were not affected, and had an average value of $29.9 \mathrm{mg} / \mathrm{dL}$. There were no differences $(P>0.05)$ in DM degradation and degradability rates. The use of high degradability protein sources, such as soybean cake and peanut cake, proved to be an interesting alternative to replace soybean meal.
\end{abstract}

Keywords: degradability, oleaginous cake, pH, ruminal ammonia concentration

\section{INTRODUÇÃO}

Conhecer a degradabilidade dos alimentos é essencial para formular dietas a serem fornecidas aos animais, sendo importante calcular os requerimentos proteicos $\mathrm{e}$ atender as necessidades dos microrganismos ruminais que, por sua vez, são capazes de transformar compostos nitrogenados não proteicos em proteína microbiana, proporcionando produção mais eficiente (Cabral et al., 2005).

A técnica in situ, apesar de sofrer várias críticas, como restrição ao acesso microbiano à proteína (Meyer e Mackie, 1986), contaminação microbiana dos sacos (Nocek e Grant, 1987) e

Recebido em 10 de maio de 2011

Aceito em 24 de maio de 2012

E-mail: vivianecorreasantos@gmail.com

Apoio financeiro: Fundação de Amparo à Pesquisa do Estado de São Paulo - FAPESP. 
perda de nitrogênio que não foi degradado, ainda é amplamente utilizada para a identificação das degradabilidades (Cabral et al., 2005). No Brasil, estudos são realizados com a utilização dessa técnica para avaliar forragens, resíduos orgânicos e produtos industriais na alimentação de bovinos.

A natureza do alimento e o ambiente ruminal proporcionado pela combinação dos ingredientes da dieta são fatores que podem influenciar a degradabilidade ruminal. A técnica in situ permite que a obtenção da extensão da digestão proteica e dos carboidratos seja avaliada considerando-se todas as variações nos eventos digestivos que ocorrem no animal (Casali et al., 2009). Deve-se salientar que a degradação ruminal envolve não apenas o desaparecimento dos nutrientes, mas também todos os eventos que dela participam, desde a ingestão do alimento até a formação de produtos finais oriundos de carboidratos e proteínas (Marcondes et al., 2009). Assim, fermentação e digestão são processos desencadeados pela degradação (Owens e Zinn, 1993; Leão et al., 2005).

A introdução de tortas na alimentação animal tem demonstrado serem estas uma alternativa alimentar viável, proporcionando bons resultados (Correia et al., 2011). Elas apresentam grande potencial, haja vista as consideráveis concentrações de proteína e extrato etéreo, que as caracterizam como alimentos proteicos e/ou energéticos, capazes de permitir o atendimento das exigências nutricionais destas frações pelos animais. Assim, o objetivo deste trabalho foi estudar a inclusão de fontes proteicas alternativas resultantes do processamento de oleaginosas destinadas à produção de biodiesel na alimentação de ovinos, bem como os efeitos sobre a degradabilidade ruminal, o $\mathrm{pH}$ e as concentrações de nitrogênio amoniacal.

\section{MATERIAL E MÉTODOS}

Quatro dietas isonitrogenadas - 18\% de proteína bruta (PB) na matéria seca (MS) - foram formuladas segundo NRC (Nutrient..., 2006), com proporção volumoso:concentrado de 30:70, tendo sido utilizado como volumoso o feno de capim- tifton moído. Os concentrados foram compostos por milho em grão moído e farelo de soja ou tortas de soja, girassol ou amendoim, e calcário calcítico, antioxidante e mistura mineral, conforme as dietas: FS - controle com $30 \%$ de farelo de soja, TS - 39\% de torta de soja como concentrado, TG - 30\% de torta de girassol como concentrado e TA - $30 \%$ de torta de amendoim como concentrado (Tab. 1).

Tabela 1. Proporção dos ingredientes e composição química e energética das dietas experimentais (\% MS)

\begin{tabular}{lcccc} 
& \multicolumn{3}{c}{ Dietas } \\
\cline { 2 - 5 } Ingredientes (\%) & $\mathrm{FS}^{1}$ & $\mathrm{TS}^{2}$ & $\mathrm{TG}^{3}$ & $\mathrm{TA}^{4}$ \\
\hline Feno de capim-tifton & 30,00 & 30,00 & 30,00 & 30,00 \\
Milho em grão moído & 45,40 & 45,40 & 45,40 & 45,40 \\
Farelo de soja & 23,00 & 14,00 & 14,00 & 14,00 \\
Torta de soja & - & 9,00 & - & - \\
Torta de girassol & - & - & 9,00 & - \\
Torta de amendoim & - & - & - & 9,00 \\
BHT & 0,10 & 0,10 & 0,10 & 0,10 \\
Calcário calcítico & 0,50 & 0,50 & 0,50 & 0,50 \\
Mistura mineral* & 1,00 & 1,00 & 1,00 & 1,00 \\
Total & 100,00 & 100,00 & 100,00 & 100,00 \\
\hline Composição & & & & 18,26 \\
\hline Proteína bruta (\% MS) & 18,72 & 18,04 & 18,00 & 4,04 \\
Extrato etéreo (\% MS) & 2,82 & 3,92 & 4,01 & 39,82 \\
Fibra em detergente neutro (\% MS) & 38,24 & 39,06 & 43,97 & 2,52 \\
Energia metabolizável (Mcal/kg MS) ** & 2,51 & 2,53 & 2,51 & . \\
\hline
\end{tabular}

${ }^{1}$ FS: controle com farelo de soja; ${ }^{2} \mathrm{TS}$ : formulada com torta de soja; ${ }^{3} \mathrm{TG}$ : formulada com torta de girassol; ${ }^{4} \mathrm{TA}$ : formulada com torta de amendoim.

Mistura mineral comercial para ovinos $(\mathrm{P}=60 \mathrm{~g} ; \mathrm{Ca}=100 \mathrm{~g} ; \mathrm{Na}=195 \mathrm{~g} ; \mathrm{Mg}=10 \mathrm{~g} ; \mathrm{S}=25 \mathrm{mg} ; \mathrm{Zn}=4.000 \mathrm{mg} ; \mathrm{Cu}=600 \mathrm{mg}$; $\mathrm{Mn}=600 \mathrm{mg} ; \mathrm{Fe}=1.200 \mathrm{mg} ; \mathrm{Co}=100 \mathrm{mg} ; \mathrm{I}=180 \mathrm{mg} ; \mathrm{Se}=12 \mathrm{mg} ; \mathrm{Fl}$ (máximo)=600mg).

$* * \mathrm{EM}=0,82 \mathrm{ED}$ (Sniffen et al. 1992) 
Para determinar o $\mathrm{pH}$ e a concentração de amônia no líquido ruminal, foram colhidas amostras de fluido ruminal, cerca de $100 \mathrm{~mL}$, de quatro ovinos machos não castrados da raça Santa Inês, fistulados no rúmen, nos tempos: uma hora antes da alimentação da manhã, no momento da alimentação (0h) e uma, três, seis e oito horas após, nos quatro períodos experimentais.

$\mathrm{O}$ pH foi medido imediatamente após a colheita e a filtragem, com peagâmetro digital. Em seguida, foi determinada a concentração de nitrogênio amoniacal, segundo a técnica de Vieira (1980). O processo é dividido em duas etapas: a destilação da amostra em aparelho tipo micro-kjeldhal e a titulação ácida. Para a realização da destilação, foi utilizada uma alíquota de $2 \mathrm{~mL}$ de líquido ruminal por amostra. Posteriormente, a amostra foi colocada em tubos de proteína e acoplada ao aparelho para realização da destilação. Após, adicionaram-se $5 \mathrm{~mL}$ de hidróxido de potássio à amostra na concentração de $2 \mathrm{~mol} / \mathrm{L}$. O destilado foi recebido em um recipiente contendo $10 \mathrm{~mL}$ de ácido bórico $2 \%$, utilizado como indicador, até completar o volume de $50 \mathrm{~mL}$. Finalmente, a titulação foi realizada com ácido clorídrico, na concentração de $0,005 \mathrm{~mol} / \mathrm{L}$, e foi calculada a concentração de amônia ruminal.

No ensaio de degradabilidade, os animais foram alimentados duas vezes ao dia (de manhã e ao final da tarde) e adaptados por 15 dias às dietas. Foi empregada a técnica de degradação ruminal in situ (Orskov e Mcdonald, 1979), utilizando-se sacos de náilon $100 \%$ poliamida, com poros de 50 micrômetros, com área disponível correspondendo a $14,0 \times 7,0 \mathrm{~cm}$, contendo, aproximadamente, 5 gramas de matéria seca, à relação de $20 \mathrm{mg} \mathrm{MS} / \mathrm{cm}^{2}$. As fontes proteicas (farelo de soja, tortas de soja, girassol e amendoim) foram moídas a $2 \mathrm{~mm}$.

Os tempos de permanência no rúmen utilizados para o farelo de soja, a torta de soja, a de girassol e a de amendoim foram de três; seis; 12; 24; 48 e 72 horas. Os sacos de náilon foram inseridos no rúmen, em ordem inversa de tempo, presos a uma corrente.

Para a determinação da fração solúvel (a), procedeu-se à lavagem dos sacos com água, em temperatura ambiente, sem incubação ruminal prévia. Após a retirada das amostras incubadas, procedeu-se à leve lavagem em balde com água fria, para interromper a fermentação microbiana, onde elas permaneceram por 10 minutos, tendo sido retirada a maior porção do conteúdo ruminal aderido. Posteriormente, os sacos foram lavados em balde com renovação de água, sendo o tempo (cinco minutos para cada) e o número de batidas com a mão (cinco) padronizados para todas as lavagens. Após esta etapa, os sacos contendo os resíduos não degradados no rúmen foram secos em estufa de circulação e renovação de ar, à temperatura de $55^{\circ} \mathrm{C}$, por um período de 72 horas.

Para a avaliação da degradabilidade potencial das frações da matéria seca, foi utilizado o modelo $\mathrm{p}$ $=\mathrm{A}+\mathrm{B}\left(1-\mathrm{e}^{(\mathrm{Kdt})}\right)$, em que: $\mathrm{p}$ é a degradação potencial do componente nutritivo, em porcentagem; A corresponde à fração solúvel, em porcentagem; $B$ é a fração insolúvel potencialmente degradável, em porcentagem; A + B representa o potencial de digestão do componente nutritivo; $\mathrm{Kd}$ é a taxa de digestão por ação fermentativa, em porcentagem por hora; e t é o tempo de incubação, em horas (Orskov e Mcdonald, 1979). A degradabilidade efetiva da matéria seca foi calculada pelo modelo: $\mathrm{DE}=\mathrm{A}$ $+\mathrm{B} \mathrm{Kd} /(\mathrm{Kd}+\mathrm{kp})$, em que $\mathrm{kp}$ é a taxa de passagem do alimento pelo rúmen.

Para os valores de $\mathrm{pH}$, concentrações de nitrogênio amoniacal e degradabilidade, o delineamento foi o quadrado latino $(4 \times 4)$, com quatro dietas e quatro períodos, analisados por regressão. Os resultados obtidos foram submetidos à análise de variância pelo procedimento estatístico PROC MIXED (Statistical..., 2001), com esquema de análises em parcelas subdivididas, sendo a parcela principal as dietas e as subparcelas os tempos de colheita. As médias foram comparadas pelo teste de Tukey, a 5\% de probabilidade.

\section{RESULTADOS E DISCUSSÃO}

Não foi observado efeito da interação tempo $x$ dieta para os valores de $\mathrm{pH}$ e concentrações ruminais de nitrogênio amoniacal $(\mathrm{P}>0,05)$. $\mathrm{O}$ $\mathrm{pH}$, variável indicativa da fermentação ruminal, não foi afetado pela inclusão de subprodutos de oleaginosas na dieta, tendo apresentado valor médio de 6,2 (Fig. 1). A variação média de pH, em função dos tempos de colheita, apresentou comportamento cúbico. 
Provavelmente, o elevado valor de $\mathrm{pH}$ ruminal verificado no início da alimentação esteja relacionado à baixa quantidade de nutrientes disponíveis para o metabolismo microbiano ruminal e à atividade de ruminação dos animais. Esta estimula a produção de saliva que, segundo Allen (1997), é um importante mecanismo para a remoção do íon $\mathrm{H}^{+}$da solução ruminal, pois contém carbonato que, ligado ao $\mathrm{H}^{+}$, forma água e $\mathrm{CO}_{2}$. Por outro lado, a queda no $\mathrm{pH}$ ruminal após o início da alimentação pode ser justificada pelo aumento de carboidratos provenientes das dietas, altamente fermentescíveis no rúmen, e pela consequente produção dos ácidos graxos de cadeia curta, os quais, com o passar do tempo, são absorvidos pelo epitélio ruminal, explicando também a redução nos valores de $\mathrm{pH}$ (Fig. 1). Ou seja, a queda da atividade microbiana provocou diminuição da produção de saliva e, consequentemente, do $\mathrm{pH}$.

Não houve efeito no $\mathrm{pH}$ ruminal para os diferentes subprodutos de oleaginosas, provavelmente, pelo consumo de FDN próximo entre as dietas avaliadas, não tendo havido, assim, nem efeito de $\mathrm{pH}$ nem de carboidratos no processo de digestão.

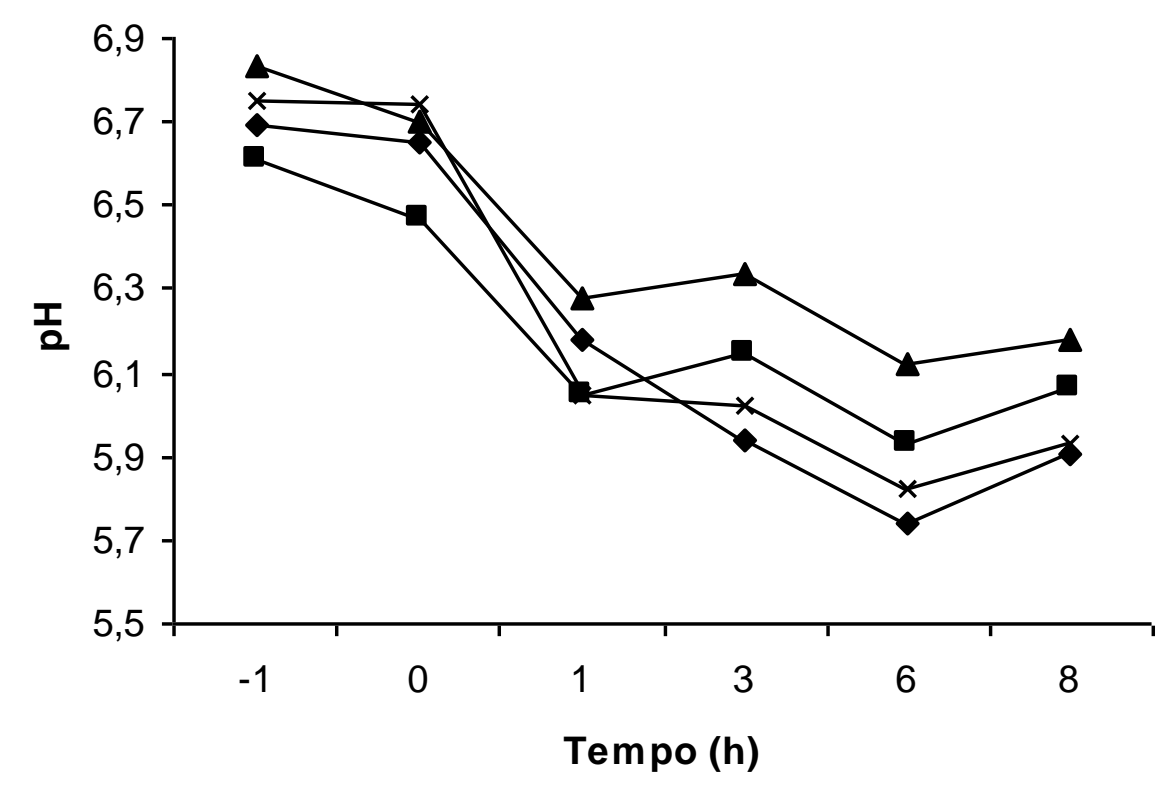

Equação de regressão em função dos tempos de colheita: $y=-0,0006 x^{3}+0,0255 x^{2}+0,2264 x+6,5019 ; R^{2}=0,79$. $\mathrm{R} 2$ = coeficiente de determinação.

FS: controle com farelo de soja; TS: formulada com torta de soja; TG: formulada com torta de girassol; TA: formulada com torta de amendoim.

Figura 1. Valores de $\mathrm{pH}$ no fluido ruminal de cordeiros alimentados com subprodutos de oleaginosas.

Dois nutrientes podem proporcionar forte impacto no pH ruminal: a concentração de CNF, que pode promover a queda no $\mathrm{pH}$, ou a concentração de EE, que pode inibir a fermentação ruminal, quando próxima ou superior a $6 \%$ na MS. Estes valores mínimos foram encontrados seis horas após a alimentação, tendo ficado abaixo de 6,2 , considerado limite mínimo para a adequada fermentação da fibra (Van Soest, 1994).
As concentrações ruminais de nitrogênio amoniacal não foram afetadas pela inclusão de subprodutos de oleaginosas na dieta, e o valor médio foi de 29,9mg/dL (Fig. 2). A variação média das concentrações de nitrogênio amoniacal, em função dos tempos de colheita, apresentou comportamento quadrático. 


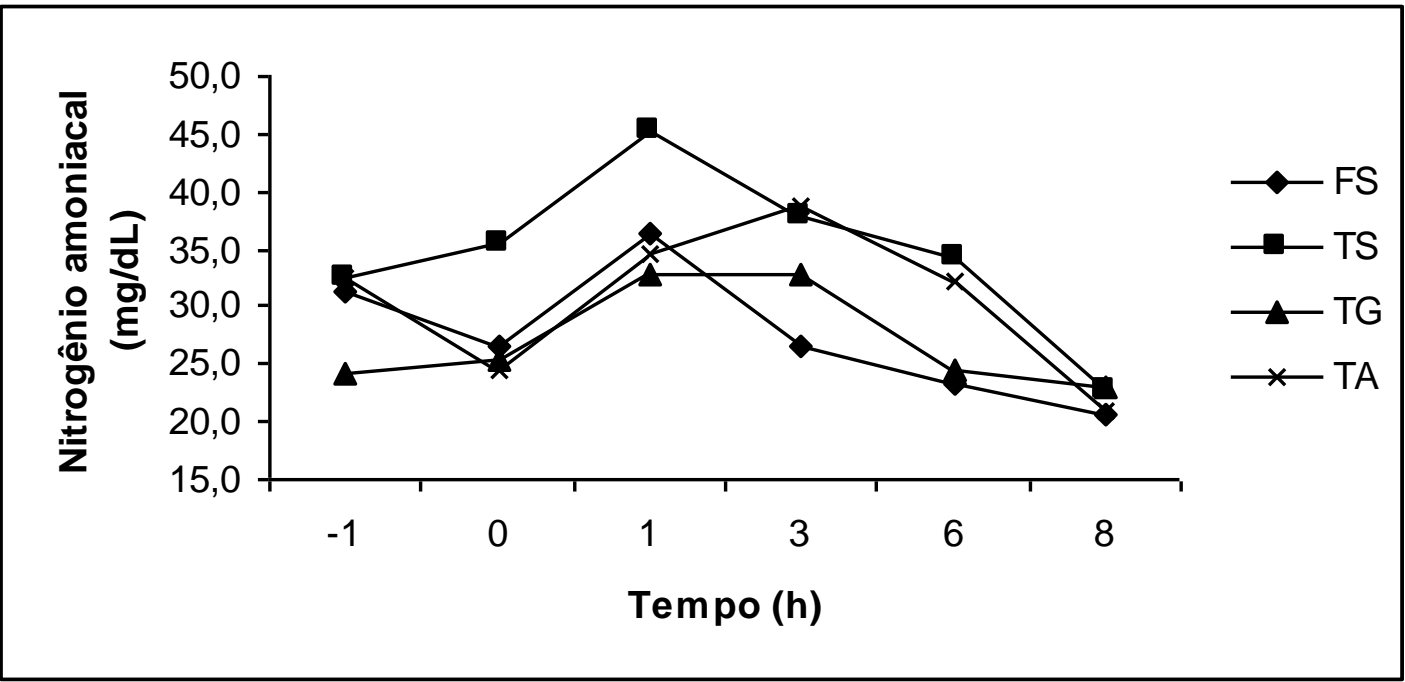

Equação de regressão em função dos tempos de colheita: $y=-0,4408 x^{2}+2,2286 x+31,786 ; R^{2}=0,46$. $\mathrm{R} 2$ = coeficiente de determinação.

FS: controle com farelo de soja; TS: formulada com torta de soja; TG: formulada com torta de girassol; TA: formulada com torta de amendoim.

Figura 2. Valores das concentrações de nitrogênio amoniacal no fluido ruminal de cordeiros alimentados com subprodutos de oleaginosas.

A concentração de nitrogênio amoniacal no rúmen apresentou pico uma hora após a alimentação; entretanto, na dieta TS, o pico de nitrogênio amoniacal ocorreu menos de uma hora após a alimentação. Certos fatores podem estar envolvidos nessa avaliação, como a energia da dieta, que foi em média de $2,52 \mathrm{Mcal} / \mathrm{kg} \mathrm{MS}$, e o número de refeições que propicia maior fermentação dos carboidratos e proteínas no rúmen. Neste experimento foram efetuadas duas refeições.

Pode-se evidenciar que a dieta com inclusão de torta de soja apresentou concentrações acima do recomendado por Preston (1986). A maior concentração de amônia observada para a torta de soja pode ser atribuída ao fato de que menor pH diminui a absorção de amônia pela parede ruminal, ficando mais disponível no rúmen, e/ou o menor $\mathrm{pH}$ pode ter prejudicado o crescimento microbiano e, com isso, a amônia disponível não foi bem utilizada pelos microrganismos. Porém, no presente trabalho, não é possível afirmar até que ponto a diferença observada no $\mathrm{pH}$ afetou a absorção de amônia, e se foi esta a causa de sua maior concentração nesta dieta.
A fração zero hora, que caracteriza a fração solúvel, foi semelhante entre as dietas, ou seja, a perda por lavagem não diferiu entre os subprodutos. A taxa de degradação (Kd) é o principal determinante da disponibilidade de energia e proteína para os microrganismos, podendo influenciar a eficiência e a quantidade de proteína microbiana sintetizada. Contudo, não foram observadas diferenças $(\mathrm{P}>0,05)$ nas taxas de degradação da MS dos subprodutos e na degradabilidade potencial (Tab. 2).

A torta de girassol apresentou maior fração indegradável $(\mathrm{C})(\mathrm{P}<0,05)$, o que refletiu em menor degradabilidade efetiva, cerca de $13,26 \%$ menor em relação aos demais subprodutos. Existem algumas hipóteses que podem ser exploradas. As menores degradabilidade e digestibilidade da matéria orgânica podem refletir a eficiência de síntese de proteína microbiana e a produção de ácidos graxos de cadeia curta. A torta de girassol também foi o alimento proteico que apresentou a menor degradação efetiva da MS (Tab. 2), em decorrência, provavelmente, de sua alta proporção de FDA. 
Influência de subprodutos de oleaginosas...

Tabela 2. Médias dos valores obtidos para as frações A, B e C, a taxa de degradação e as degradabilidades potencial e efetiva para a matéria seca dos subprodutos de oleaginosas, incubados nas diferentes dietas

\begin{tabular}{lccccc} 
& \multicolumn{3}{c}{ Subprodutos } & $*$ \\
\cline { 2 - 5 } Variável & FS & TS & TG & TA & \\
\hline A $(\%)$ & 27,97 & 26,74 & 25,67 & 27,78 & 1,40 \\
B $(\%)$ & 54,45 & 54,05 & 53,38 & 54,17 & 1,17 \\
C $(\%)$ & $17,58 \mathrm{~b}$ & $19,21 \mathrm{~b}$ & $20,94 \mathrm{a}$ & $18,05 \mathrm{~b}$ & 1,86 \\
Kd $(\% / \mathrm{h})$ & 5,33 & 5,17 & 4,15 & 5,37 & 2,69 \\
DP $(\%)$ & 82,00 & 80,40 & 77,95 & 81,52 & 2,20 \\
DE $(5 \% / \mathrm{h})$ & $55,41 \mathrm{a}$ & $56,23 \mathrm{a}$ & $48,57 \mathrm{~b}$ & $56,48 \mathrm{a}$ & 3,98 \\
\hline
\end{tabular}

FS: farelo de soja; TS: torta de soja; TG: torta de girassol; TA: torta de amendoim.

$\mathrm{A}=$ fração solúvel, $\mathrm{B}=$ fração insolúvel potencialmente degradável, $\mathrm{C}=$ fração indegradável, $\mathrm{KD}=$ taxa de degradação, $\mathrm{DP}=$ degradabilidade potencial, $\mathrm{DE}=$ degradabilidade efetiva, $* \mathrm{EP}=$ erro-padrão da diferença entre as médias.

Médias seguidas por letras diferentes, na linha, diferem entre si pelo teste Tukey $(\mathrm{P}<0,05)$.

O farelo de soja é um dos alimentos com maior quantidade de informações na literatura. A fração A encontrada para esse alimento foi inferior àquela comumente observada (Souza et al., 2000; Moreira et al., 2003; Oliveira et al., 2003; Cabral et al., 2005; Marcondes et al., 2009). Apesar de todos os trabalhos terem sido realizados com sacos de náilon para fazer a degradação da MS, Casali et al. (2009) mostraram que esse material tem alta porosidade, o que acarreta maiores erros de estimação da fração A.

Entre os subprodutos proteicos, a torta de soja e a torta de amendoim foram os que apresentaram maior potencial de substituição ao farelo de soja, pois suas degradações efetivas da matéria seca foram bem próximas à desse alimento.

A torta de amendoim apresenta alta variabilidade na degradação ruminal, e as frações A e B foram diferentes das descritas na literatura, de 58,02 e 36,43 (Marcondes et al., 2009), o que parece estar relacionado à própria variabilidade desse alimento no mercado. A falta de padronização desse subproduto no mercado pode influenciar significativamente os resultados da pesquisa.

Goes et al. (2004), ao avaliarem a degradabilidade ruminal de diferentes ingredientes, em novilhos fistulados no rúmen, verificaram solubilidade da matéria seca (pelo método da lavagem dos sacos de náilon) do farelo de amendoim de 20,0\%, e uma degradabilidade efetiva (DE) de 60,8\%, à taxa de passagem (Kp) de $5 \% / \mathrm{h}$, valores próximos aos encontrados no presente experimento, utilizando torta de amendoim com dados médios de $27,8 \%$ de solubilidade e $56,48 \%$ de degradabilidade efetiva.

Kamalak et al. (2005), ao avaliarem a degradabilidade de diferentes fontes proteicas em ovinos fistulados no rúmen, verificaram solubilidade da matéria seca do farelo de soja, pelo método da lavagem dos sacos de náilon, de $28,0 \%$, e degradabilidade efetiva a $5 \% / \mathrm{h}$ de $55,4 \% / \mathrm{h}$, valores próximos aos obtidos no presente estudo.

Não foi observada diferença $(\mathrm{P}>0,05)$ na taxa de degradação da proteína. Porém, foi verificada diferença $(\mathrm{P}<0,05)$ na $\mathrm{DE}$. A torta de girassol ofereceu menor degradabilidade efetiva em relação aos demais subprodutos em, aproximadamente, $15,3 \%$.

Resultados diferentes da literatura foram observados neste trabalho para a degradação ruminal da $\mathrm{PB}$ do farelo de soja e da torta de amendoim. Marcondes et al. (2009) encontraram 67,30; 32,71; 90,37 e 78,03 para A, B, DP e DE, respectivamente. A torta de amendoim é um alimento de composição muito variável, principalmente em virtude dos teores de proteína e extrato etéreo, o que pode ter contribuído para essa variabilidade dos resultados. 
Tabela 3. Médias dos valores obtidos para as frações A, B e C, a taxa de degradação e as degradabilidades potencial e efetiva para a proteína bruta dos subprodutos de oleaginosas incubados nas diferentes dietas

\begin{tabular}{|c|c|c|c|c|c|}
\hline \multirow[b]{2}{*}{ Variável } & \multicolumn{4}{|c|}{ Subprodutos } & \multirow[b]{2}{*}{ *EP } \\
\hline & $\mathrm{FS}$ & $\mathrm{TS}$ & TG & TA & \\
\hline $\mathrm{A}(\%)$ & $24,52 \mathrm{a}$ & $21,34 a$ & $21,14 b$ & $22,26 a$ & 0,79 \\
\hline $\mathrm{B}(\%)$ & 69,22 & 67,15 & 65,19 & 67,30 & 1,96 \\
\hline $\mathrm{C}(\%)$ & $6,26 c$ & $11,52 \mathrm{ab}$ & $13,67 \mathrm{a}$ & $10,44 b$ & 1,10 \\
\hline $\mathrm{Kd}(\% / \mathrm{h})$ & 4,21 & 5,08 & 3,93 & 5,34 & 2,29 \\
\hline DP $(\%)$ & $92,50 \mathrm{a}$ & $87,98 \mathrm{a}$ & $84,72 b$ & $89,05 \mathrm{a}$ & 1,05 \\
\hline DE $(5 \% \mathrm{~h})$ & $55,47 \mathrm{a}$ & $57,70 \mathrm{a}$ & $48,26 \mathrm{~b}$ & $57,90 \mathrm{a}$ & 3,62 \\
\hline
\end{tabular}

FS: farelo de soja; TS: torta de soja; TG: torta de girassol; TA: torta de amendoim.

$\mathrm{A}=$ fração solúvel, $\mathrm{B}=$ fração insolúvel potencialmente degradável, $\mathrm{C}=$ fração indegradável, $\mathrm{KD}=$ taxa de degradação, $\mathrm{DP}=$ degradabilidade potencial, $\mathrm{DE}=$ degradabilidade efetiva, $* \mathrm{EP}=$ erro-padrão da diferença entre as médias.

Médias seguidas por letras diferentes, na linha, diferem entre si pelo teste Tukey $(\mathrm{P}<0,05)$.

As degradabilidades potencial e efetiva da torta de soja e da torta de amendoim foram semelhantes, demonstrando que estes ingredientes podem substituir o farelo de soja quanto à fração proteica.

A degradabilidade efetiva da torta de girassol foi menor $(\mathrm{P}>0,05)$, demonstrando que esse ingrediente pode não ser extensamente degradado no rúmen e, assim, não ser utilizado como potencial fonte proteica. Tal comportamento pode estar associado aos efeitos do processamento pelo qual foi submetido no momento da extração do óleo. $\mathrm{O}$ fornecimento de fontes proteicas de baixa degradabilidade ruminal possibilita a manipulação do perfil aminoacídico que chega ao duodeno. Entretanto, este artifício nutricional pode não proporcionar bons resultados, devido ao baixo suprimento de nitrogênio no rúmen para síntese microbiana (Leão et al., 2005). Sendo as exigências proteicas dos ruminantes atendidas pelos aminoácidos de origem dietética e microbiana que são absorvidos no intestino, o fornecimento de substrato proteico e energético, no ambiente ruminal, pode favorecer sua síntese (Leão et al., 2005).

\section{CONCLUSÕES}

A torta de soja e a torta de amendoim podem ser utilizadas em substituição ao farelo de soja na alimentação de ovinos, pois não afetam o pH e a concentração de nitrogênio amoniacal do líquido ruminal e demonstraram ser fontes proteicas de elevada degradabilidade ruminal.

\section{REFERÊNCIAS}

ALLEN, M.S. Relationship between fermentation acid production in the rumen and requirement for physically effective fiber. J. Dairy Scie., v.80, p.1447$1462,1997$.

CABRAL, L.S.; VALADARES FILHO, S.C.; ZERVOUDAKIS, J.T. Degradabilidade in situ da matéria seca, da proteína bruta e da fibra de alguns alimentos. Pesq. Agrop. Bras., v.40, p.777-781, 2005.

CASALI, A.O.; DETMANN, E.; VALADARES FILHO, S.C. Estimação dos teores de componentes fibrosos em alimentos para ruminantes em sacos de diferentes tecidos. Rev. Bras. Zootec., v.38, p.130-138, 2009.

CORREIA, B.R.; OLIVEIRA, R.L.; JAEGER, S.M.P.L. et al. Consumo, digestibilidade e $\mathrm{pH}$ ruminal de novilhos submetidos a dietas com tortas oriundas da produção do biodiesel em substituição ao farelo de soja. Arq. Bras. Med. Vet. Zootec., v.63, p.356-363, 2011.

GOES, R.H.T.B.; MANCIO, A.B.; VALADARES FILHO, S.C. Degradabilidade ruminal da matéria seca e proteína bruta, de alimentos concentrados utilizados como suplemento para novilho. Cienc. Agrot., v.28, p.167-173, 2004.

KAMALAK, A.; CANBOLAT, O.; GURBUZ, Y. et al. In situ ruminal dry matter and crude protein degradability of plant and animal-derived protein sources in Southern Turkey. Small Rum. Res., v.58, p.135-141, 2005.

LEÃO, M.I.; VALADARES FILHO, S.C.; RENNÓ, L.N. et al. Consumos e digestibilidades aparentes totais e parciais de matéria seca, matéria orgânica, proteína bruta e extrato etéreo em novilhos submetidos a três níveis de ingestão e duas metodologias de coleta de digestas abomasal e novilhos submetidos a três níveis de ingestão e duas metodologias de coleta de digestas abomasal e omasal. Rev. Bras. Zootec., v.33, p.1604-1615, 2005. 
MARCONDES, M.J.; VALADARES FILHO, S.C.; DETMANN, E. et al. Degradação ruminal e digestibilidade intestinal da proteína bruta de alimentos para bovinos. Rev. Bras. Zootec., v.38, p.2247-2257, 2009.

MEYER, J.H.F.; MACKIE, R.J. Microbiological evaluation of the intraruminal in sacculus digestion technique. Appl. Envir. Microbiol., v.51, p.622-629, 1986.

MOREIRA, J.F.C.; RODRIGUEZ, N.M.; FERNANDES, P.C.C. Concentrados proteicos para bovinos: 1. Digestibilidade in situ da matéria seca e da proteína bruta. Arq. Bras. Med. Vet. Zootec., v.55, p.315-323, 2003.

NOCEK, J.E.; GRANT, A.L. Characterization of in situ nitrogen and fiber digestion and bacterial nitrogen contamination of hay crop forages preserved at different dry matter percentagem. J. Anim. Sci., v.64, p.552-564, 1987.

NUTRIENT requirements of small ruminants. Washington: National Academies, 2006. 325p.

OLIVEIRA, M.V.M.; VARGAS JUNIOR, F.M.; SANCHEZ, L.M.B. Degradablidade ruminal e digestibilidade intestinal de alimentos por intermédio da técnica in situ associada à do saco de náilon móvel. Rev. Bras. Zootec., v.32, p.2023-2031, 2003.

ØRSKOV, E.R.; McDONALD, I. The estimation of protein degradability in the rumen from incubation measurements weighted according to rate of passage. J. Agric. Sci., v.92, p.499-503, 1979.
OWENS, N.F.; ZINN, R. Metabolismo de la proteina en los rumiantes. In: CHURCH, D.C. (Ed.) El rumiannte: Fisiologia digestiva y nutrición. 5nd ed. Zaragoza: Acribia. 1993. p.255-281.

PRESTON, T.R. Analytical methods for characterizing In: FEED RESOURCES FOR RUMINANTS. Better utilization of crop residues and by products in animal feeding: research guidelines. $A$ practical manual for research workers. Rome: FAO, 1986. p.106.

SNIFFEN, C.J.; CONNOR, J.D.; VAN SOEST, P.J.A. A net carbohydrate and protein system for evaluating cattle diets: II. Carbohydrate and protein availability. J. Anim. Sci., v.70, p.3562-3577, 1992.

SOUZA, J.R.T.; CAMARÃO, A.P.; RÊGO, L.C. Degradabilidade ruminal da matéria seca e da proteína bruta de subprodutos da agroindústria, da pesca e de abatedouros em caprinos. Braz. J. Vet. Sci., v.37, 2000. Disponível em: <http://www.scielo.br/scielo.php?script= ci_arttex\&pid=S1413-

596200000015\&lng=en\&nrm=iso>. Acessado em: $17 / 6 / 2007$

STATISTICAL Analysis System-SAS Institute inc. Technical Report: SAS/STAT. Release 8.2. Cary, 2001.

VAN SOEST, P.J. Nutritional ecology of the ruminant. 2nd ed. Ithaca:Cornell. 1994. 476p.

VIEIRA, P.F. Efeito do formaldeído na proteção de proteínas e lipídios em rações para ruminantes. 1980. 98f. Tese (Doutorado em Zootecnia) - Universidade Federal de Viçosa, Viçosa, MG. 